\title{
Comparitive Study of Conventional And Topical Heparin Dressing in Lower Limb Diabetic Ulcers.
}

\author{
Dr.T.Srinivasan, M.S, ${ }^{1}$, Dr.M.Muralidharan ${ }^{2}$ \\ I'Associate Professor, Department Of General Surgery, Government Thiruvarur Medical College/Tamilnadu \\ Dr.M.G.R Medical University, India) \\ ${ }_{2}^{2}$ (Post Graduate In M.S. General Surgery, Department Of General Surgery, Coimbatore Medical \\ College/Tamilnadu Dr.M.G.R Medical University, India)
}

\begin{abstract}
:
Background: lower limb diabetic ulcers are very difficult to treat due to the poor vascularity and brittle granulation tissue formed during the healing phase. So a novel method is needed apart from conventional dressings to enhance the healing process. Such a method is to do dressing of ulcers using 200IU/ml of sodium aqueous heparin dressings.

Methods : In this prospective study conducted from may-2016 to october-2016 at department of general surgery, coimbatore medical college the diabetic ulcer foot patients were divided into two groups, one will be treated with conventional saline dressing and the other using topical aqueous heparin, the wound healing was assessed using Bates-Jensen wound assessment tool and the hospital stay, antibiotic and analgesic requirement were recorded.

Results : On statistical analysis, the hospital stay and antibiotic requirement shows significant reduction in heparin group and not so for analgesics. Wound healing was better and earlier in heparin group.

Conclusion : Topical heparin dressing of lower limb diabetic ulcers shows significant improvement in healing, reduction in hospital stay and antibiotic requirement.

Keywords: Diabetes, Heparin, Antibiotic, neovascularisation.

\section{Introduction}

Diabetic ulcers of lower limb are very difficult to treat and they contribute to a great account of morbidity and expenditure of human resources and manpower. Due to poor vascularity and brittle granulation tissue formed during wound healing phase accounts for this. A novel method is needed to overcome these factors and which promotes healing and lessens the hospital stay and morbidity. Dressing the lower limb diabetic ulcers using $200 \mathrm{IU} / \mathrm{ml}$ sodium aqueous heparin ${ }^{[1]}$ solution USP (heparin) dripped on the ulcer surfaces is such a search towards our goal. Heparin promotes migration of capillary endothelial cell ${ }^{[2,3]}$ and produces angiogenesis ${ }^{[4]}$ and thus formation of healthy granulation tissue. It also reduces bacterial translocation ${ }^{[5]}$ and necessary for antibiotics minimized. Heparin also enhances type 1 collagen synthesis ${ }^{[6,7]}$ and hence the stable granulation tissue causes better healing.
\end{abstract}

\section{Objectives Of The Study}

Primary: To prospectively compare the healing of lower limb diabetic ulcers in patients with conventional saline dressing and topical heparin saline dressing.

\section{Secondary}

To analyse and compare the parameters of

1. hospital stay

2. antibiotic requirements based on culture and sensitivity and

3. analgesia requirement.

\section{Study Design}

Prospective cohort study carried out after obtaining local ethical committee clearance.

\section{Inclusion Criteria}

\section{Methodology}

Patients admitted from MAY-2016 to OCTOBER-2016 with diabetic ulcer of lower limb at department of general surgery, Coimbatore medical college are included in the study.By systemic random sampling those patient will be divided into two groups. (H) group- wound will be dressed with heparinised saline using $200 \mathrm{IU} / \mathrm{ml}$ sodium aqueous heparin solution USP (heparin) dripped on the ulcer surfaces. 
(c) group- wound will be dressed with conventional way of normal saline or metronidazole dressing.

\section{Exclusion Criteria}

1. patients with features of sepsis,

2. peripheral arterial occlusive disorders,

3. any allergy to heparin, were excluded from this study.

\section{Analysis}

Wound healing was assessed using Bates- Jensen scoring system, and requirement of analgesics, antibiotics and duration of hospital stay were recorded and data analysed.

Table 1 - sex distribution in both conventional and heparin group

\begin{tabular}{|l|l|l|}
\hline Sex & Conventional Group & Heparin Group \\
\hline Male & 27 & 24 \\
\hline Female & 5 & 8 \\
\hline
\end{tabular}

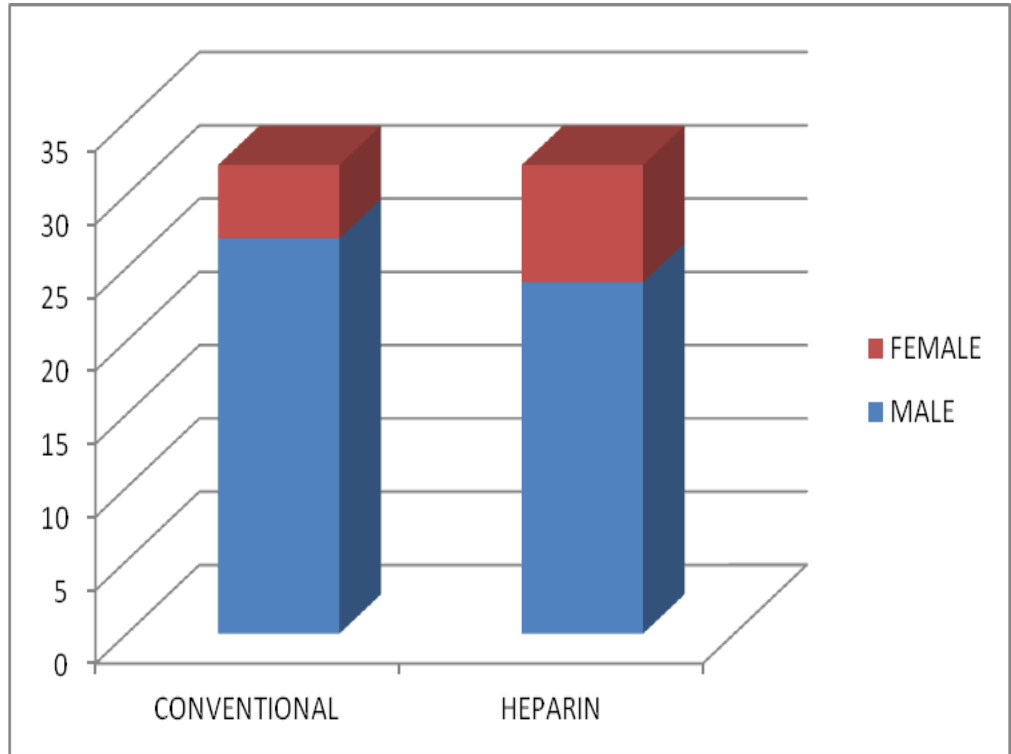

Fig 1 - sex distribution in both conventional and heparin group

Table 2 - Comparision of mean days of hospital stay

\begin{tabular}{|l|l|l|}
\hline S.No & Group & Mean Hospital Stay(Days) \\
\hline 1. & Conventional Group & 16.4 \\
\hline 2. & Heparin Group & 13.6 \\
\hline
\end{tabular}

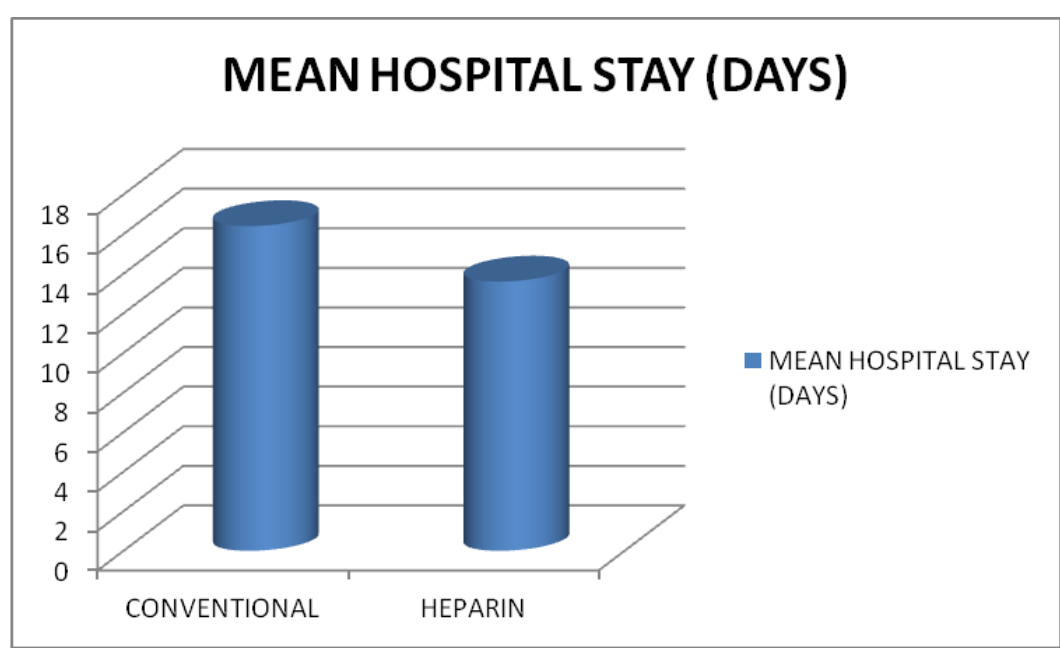

Fig 2 - Comparision of mean days of hospital stay 
Comparitive Study Of Conventional And Topical Heparin Dressing...

Table 3 - Antibiotic requirement in both group

\begin{tabular}{|l|l|l|}
\hline Antibiotics & Conventional Group & Heparin Group \\
\hline Empirical Sensitive & 20 & 28 \\
\hline Drug Revised By C\&S & 12 & 4 \\
\hline
\end{tabular}

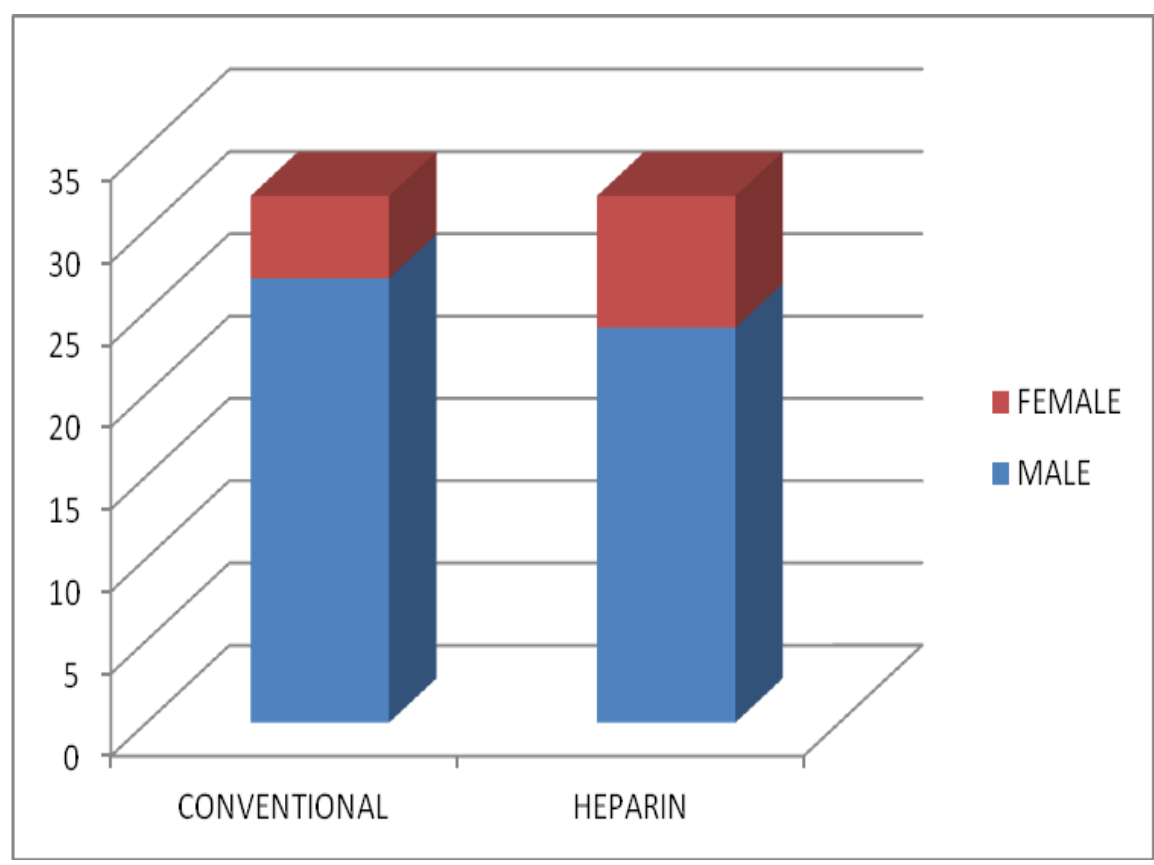

Fig 3 - Antibiotic requirement in both group

Table 4 - Analgesic requirement in both group

\begin{tabular}{|l|l|}
\hline Analgesic Needed & (Mean Doses/Day) \\
\hline Conventional Group & 2.1 \\
\hline Heparin Group & 2 \\
\hline
\end{tabular}

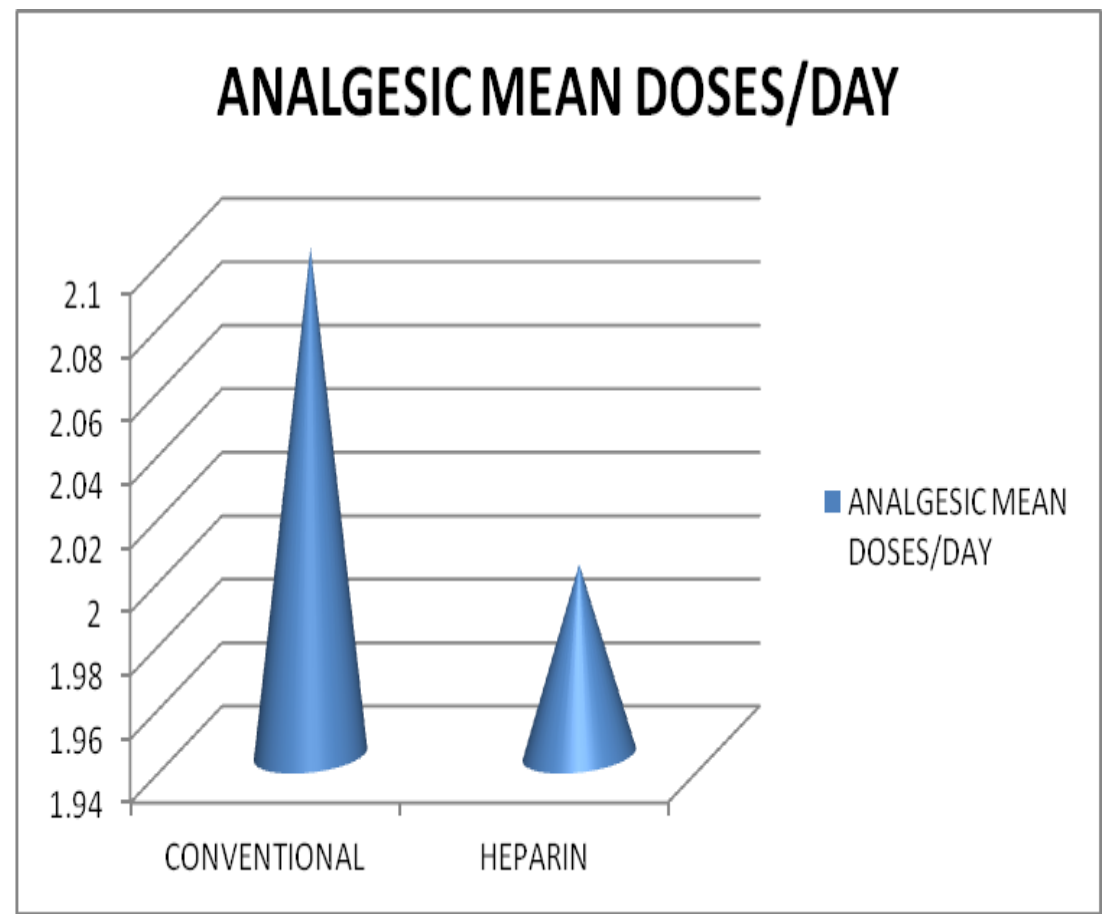

Fig 4 - Analgesic requirement in both group 
Comparitive Study Of Conventional And Topical Heparin Dressing...

Table 5 - Amputation rate in both group

\begin{tabular}{|l|l|}
\hline Group & Amputation/ Disarticulation Needed \\
\hline Conventional Group & 2 \\
\hline Heparin Group & 0 \\
\hline
\end{tabular}

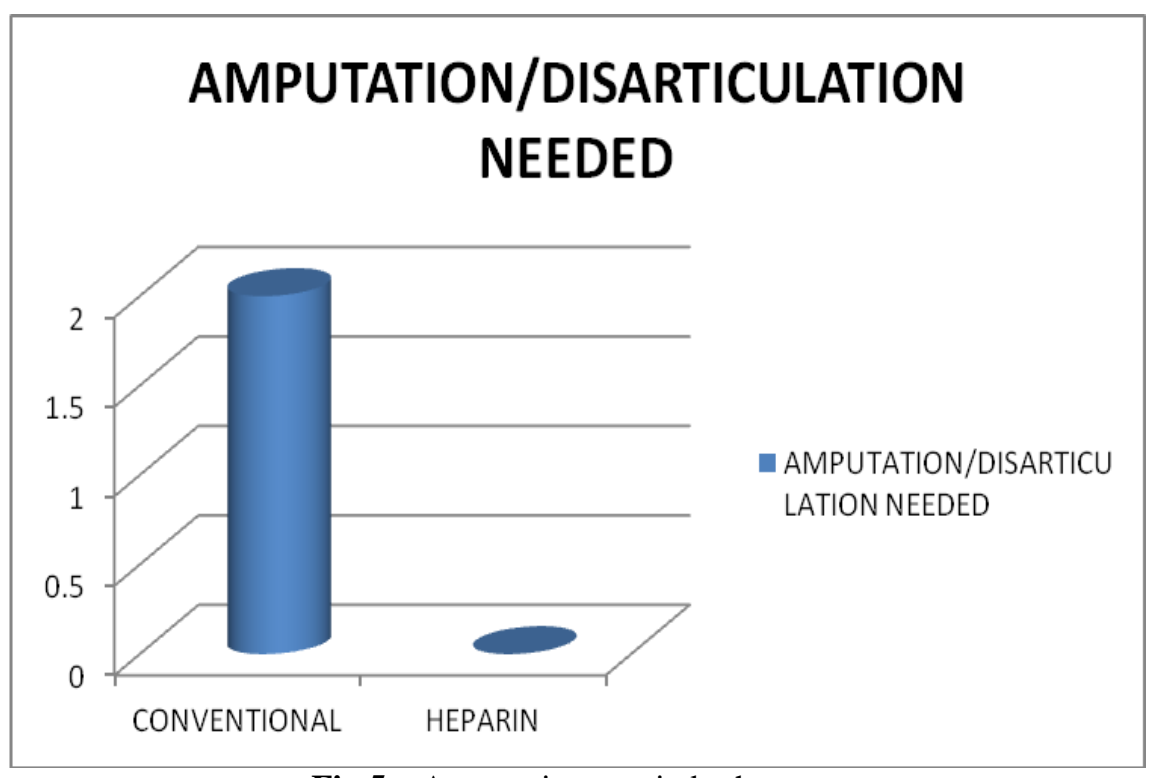

Fig 5 - Amputation rate in both group

Table 6 - serial Bates - Jensen wound healing score

\begin{tabular}{|l|l|l|}
\hline \multirow{2}{*}{ Duration (Weeks) } & Mean Bates- Jensen Wound Score \\
\cline { 2 - 3 } & Conventional Group & Heparin Group \\
\hline 0 & 27 & 28 \\
\hline 1 & 24 & 23.6 \\
\hline 2 & 21.3 & 14 \\
\hline 3 & 16 & 11.2 \\
\hline
\end{tabular}

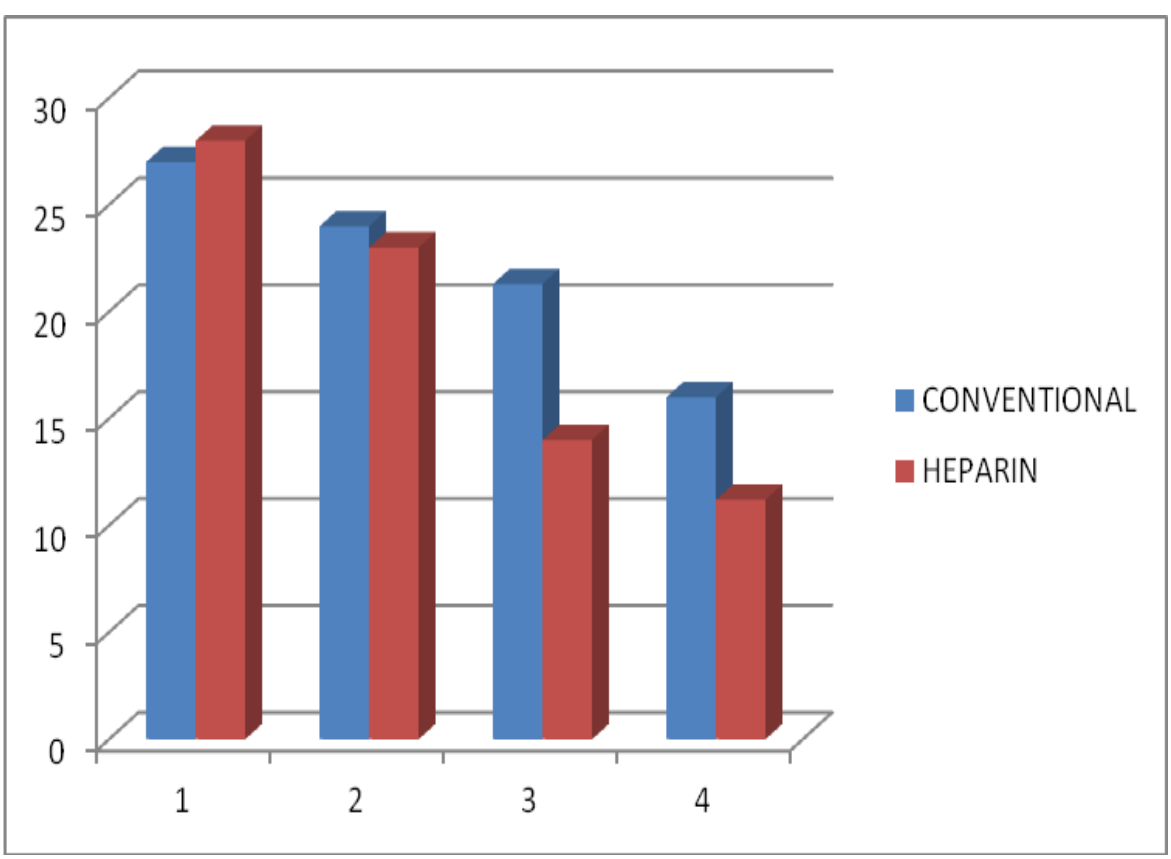

Fig 6 - serial Bates - Jensen wound healing score 


\section{Conclusion}

Using heparinised saline for dressing the lower limb diabetic ulcers provided peripheral arterial occlusion ruled out the would healing rate was faster compared to regular saline dressing. Requirement and change of antibiotics were less and due to faster recovery duration of hospital stay were also significantly reduced. Therewere no much difference in analgesic requirement. Failure of healing process and going for amputation were observed in conventional dressing group but this needs a separate study in a large sample.

\section{References}

[1]. Saliba M.J., Escamillo A.R., Ramakrishnan K.M., Jayaraman V., Zhao-fan Xia, Xu Lin Chen, Zayas J.G., da Costa M.G., Thomas C., Mlcak R., Oh J.S., Venakatachalapathy T.S., Kumar M. Syllabus of Proceedings, Sixth International Heparin Therapy In Burns, Fifth Asian Pacific Burns Congress, Shanghai, China, November 2005.

[2]. Azizkhan R.G., Azizkhan J.C., Zetter B.R., Folkman J. Mast cell heparin stimulates migration of capillary endothelial cell in vitro. J. Exp. Med. 1980;152:931-931. [PMC free article][PubMed]

[3]. Macaig T. et al. Heparin binds endothelial cell growth factor, the principal endothelial cell mitogen in bovine brain. Science. 1984;225:932-932.[PubMed]

[4]. Folkman J., Shing Y. Control of angiogenesis by heparin and other sulphated polysaccharides. Adv. Exp. Med. Biol. 1992;313:355364.[PubMed]

[5]. Zapat-Sirvant R.L., Hansbrough J.F., Greenleaf G.E. et al. Reduction of bacterial translocation and intestinal structure alterations by heparin in a murine burn injury model. J. Trauma. 1994;36:1-6.[PubMed]

[6]. Ferrao A.V., Mason R.M. The effect of heparin on cell proliferation and type I collagen synthesis by adult human dermal fibroblasts. Biochem. Biophys. Acta. 1993;1180:225-230.[PubMed]

[7]. Ehrlich H.R., Griswold T.R., Rajaratanam J.B.M. Studies on vascular smooth muscle cells and dermal fibroblast in collagen matrices: Effect of heparin. Exp. Cell Res. 1986;164:154-162.[PubMed] 